\title{
INTERNAÇÃO POR FEBRE REUMÁTICA ENTRE 5 E 14 ANOS, NA ÚLTIMA DÉCADA NO BRASIL
}

\author{
RHEUMATIC FEVER HOSPITALIZATIONS BETWEEN 5 AND 14 YEARS IN \\ THE LAST DECADE IN BRAZIL
}

Julia Corso Marafon ${ }^{1 *}$, Maria Emília Lorençatto ${ }^{1}$, Breno Henrique De Souza ${ }^{1}$, Guilherme Scatola ${ }^{2}$.

1 UNINGÁ - Centro Universitário Ingá, Maringá, PR, Brasil.

Santa Casa de Londrina, Londrina, PR, Brasil.

*julia.fon@hotmail.com

\section{RESUMO}

A febre reumática $(F R)$ trata-se de uma doença predominante na faixa etária pediátrica, que se baseia em uma complicação não supurativa da faringoamigdalite causada pelo estreptococo beta-hemolítico do grupo A (Streptococcus pyogenes) e decorre da resposta imune tardia a esta infecção em populações geneticamente predispostas. Tem como manifestação mais comum a artrite, com evolução favorável em cerca de três semanas, na grande maioria dos casos e a cardite como expressão mais grave, que contribui para a doença valvar, sequelas a longo prazo e até mesmo óbito. Seu diagnóstico é predominantemente clínico, dessa forma, a deficiência de conhecimento do profissional de saúde em relação ao manuseio clínico correto dessa doença, associado com a falta de acesso da população aos centros de centros de saúde, desinformação e situações sociais precárias, geram um problema de saúde pública, visto que a febre reumática tem como uma de suas consequências, uma afecção cardiovascular adquirida mais frequente e importante da infância. Este estudo tem como objetivo avaliar o índice de internação hospitalar, em crianças e adolescentes de 5 a 14 anos, comparando as 5 regiões do Brasil. Foi realizado um estudo ecológico observacional com componentes descritivos utilizando os dados do Departamento de Informática do Sistema Único de Saúde (DATASUS), no período de janeiro de 2009 a dezembro de 2019, no Brasil. Por meio da análise, foi evidenciado um total de 7117 casos de internamento no território nacional na última década em decorrência da FR e seus sintomas, na faixa etária especificada, o que representa um valor significativo de casos. A região nordeste foi responsável por 3296 casos, correspondendo a 46,3\% do número total. 0 Sudeste vem em segundo lugar com 1910 (26,8\%), seguido da região norte, 978 $(13,74 \%)$, e do centro-oeste com $603(8,47 \%)$. Com menor número de casos, encontra-se o Sul, apresentando 330 (4,6\%). Tendo em vista que as condições socioeconômicas desempenham um papel crítico na determinação do risco da FR, podemos relacionar a alta taxa desta patologia na região nordeste apontada nos últimos anos, com a pobreza, precariedade de condições de vida, situações sociais desfavoráveis e a falta de informação. Ademais, a profilaxia secundária, uso periódico e por longo prazo de antibióticos, visa impedir recidivas da doença em pacientes que já apresentaram um primeiro surto, deixando claro a importância do envolvimento de áreas de educação e saúde. Desta forma, oferecer treinamento e avaliação contínuos dos profissionais da saúde e, 
paralelamente, motivar a população a se engajar nessa luta contra a febre reumática, fornecendo, através de um processo educativo, subsídios para serem multiplicadores das informações ora adquiridas, acreditando que só através da educação e difusão do conhecimento, será minimizada a incidência dessa doença no Brasil.

Palavras-chave: Complicações da febre reumática. Faixa etária. Febre reumática. Nível socioeconômico. Regiões brasileiras. 